\title{
Lactation and the physiology of prolactin secretion
}

\author{
A. S. McNeILly \\ Ph.D. \\ Departments of Chemical Pathology, and Obstetrics and Gynaecology, \\ St Bartholomew's Hospital Medical College, London E.C.1
}

\section{Summary}

Prolactin in man appears to form an essential part of the complex of hormones necessary for milk secretion and lactation. Levels of prolactin during pregnancy gradually increase towards term, and remain elevated for up to 6 weeks post partum. The lactogenic effects of prolactin appear to be blocked at the mammary gland by the elevated levels of fetoplacental steroids secreted during pregnancy. The immediate decline in steroid levels at delivery removes this block to prolactin and milk secretion ensues.

The amenorrhoea associated with both puerperal lactation and galactorrhoea appears to reflect failure of cyclical discharge of gonadotrophins and anovulation. This appears to be due to peripheral inhibition of steroidogenesis by the elevated levels of prolactin associated with these situations. No consistent changes in circulating levels of prolactin occur during the menstrual cycle, but changes in prolactin levels within the follicular fluid of the developing ovarian follicle indicate a specific and permissive role of prolactin in steroidogenesis.

\section{Introduction}

Although in animal species over eighty-two actions for prolactin have been suggested, a major function in mammals, as suggested by its name, is in lactation. Much work has been carried out in animals to investigate those factors which contribute to milk secretion; in several species a well defined complex of hormones, including prolactin, has been elucidated. By contrast, in man, little is known of the hormonal control of either mammary growth (mammogenesis), or milk secretion (lactogenesis), and much of the information available has been derived from indirect evidence. A major stumbling block in our understanding of human lactation has been the controversy over the existence of a distinct prolactin molecule in the human. Despite pioneering work by Pasteels in the 1960's, human prolactin in pure form was not isolated until 1970. Since then, with the introduction and widespread use of specific radioimmunoassays, a wealth of data has been accumulated from man which sheds light not only on the role of prolactin in lactation, but also on its role in reproduction.

\section{Prolactin and lactation \\ Mammary growth}

Whether prolactin plays a role in the growth of the mammary gland is uncertain. There is no evidence to suggest that prolactin levels alter at puberty. It is apparent, however, that prolactin forms part of a complex of hormones necessary for normal mammary development. Thus, Contesso, Ceriani and Nata (1972) have shown that growth and differentiation of human female mammary tissue in culture is dependent not only on prolactin, but also requires growth hormone, insulin, oestrogen and progesterons. Whether growth hormone is an important part of thie complex is uncertain, since mammary ductal growth occurred after ethinyl oestradiol treatment in hypopituitary men without measurable growth hormone (Frantz, 1972).

\section{Prolactin and milk secretion}

The role of prolactin in the control of milk secretion in animals is now reasonably well understood. It is apparent that prolactin forms part of a complex of hormones (including growth hormone and insulin) necessary to maintain milk secretion; only in the rabbit can milk secretion be maintained by prolactin alone (see Cowie and Tindal, 1972). At the level of the secretory alveolar cell in the mammary gland, prolactin binds to specific receptor sites at the plasma membrane (Falconer, 1972; Turkington, Frantz and Majumder, 1973; Shiu, Kelly and Friesen, 1973), and induces formation of RNA and subsequently the formation of the characteristic milk proteins and secretion into the ductal system of the gland (Turkington et al., 1973). The action of the alveolar cell appears to be mediated via the surface receptor, since Turkington (1970) has demonstrated that prolactin coupled to sepharose beads, which would prevent entry into the cell, can stimulate isolated mammary epithelial cells. 
Whether prolactin plays a similar role in promoting milk synthesis and secretion in the human is uncertain, but seems likely since human prolactin, in common with prolactin from other species, binds to mammary receptors (Shiu et al., 1973) and can induce milk secretion in explants of mammary tissue (see review by Forsyth and Parke, 1973).

\section{Circulating levels of prolactin and lactation}

In the traditional view, prolactin release was thought to begin in the early puerperium and to be responsible for milk secretion in the breast which had previously been prepared by other factors, in particular the fetoplacental steroids during pregnancy. But direct measurement of prolactin levels reveals a different picture. During pregnancy, circulating levels of prolactin show a gradual rise to reach a maximum at term (Tyson et al., 1972; Jaffe et al., 1973; Robyn et al., 1973; Evans, McNeilly and Chard, 1975). After delivery, prolactin levels fall but basal concentrations do not reach the non-pregnant range until at least 2 weeks post partum.

Milk secretion begins only at the time of delivery, in spite of the high levels of circulating lactogenic hormones, prolactin and human placental lactogen, during pregnancy. This suggests that the lactogenic activity of prolactin is opposed by the high levels of oestrogens and progesterone which circulate during the latter part of pregnancy. Immediately after delivery, the levels of fetoplacental steroids decline rapidly, while those of prolactin are maintained (Reyes, Winter and Faiman, 1972); the removal of steroid inhibition thus permits prolactin to exert its normal action on the stimulation of milk secretion. Jaffe et al. (1973) have shown that administration of oestradiol valerate and testosterone enanthate (deladumone) for suppression of lactation does not alter the secretion of prolactin, further indicating steroid mediated suppression of prolactin at the breast.

During puerperal lactation, prolactin levels fluctuate widely (Reyes et al., 1972; Jaffe et al., 1973) owing to release in association with suckling (Hwang, Guyda and Friesen, 1971).

The response to suckling may vary with time after delivery, and Tyson et al. (1972) have shown that as lactation advances, the amount of prolactin released in response to suckling decreases. These changes are unrelated to the amount of milk produced, since milk production remains reasonably constant despite wide fluctuations in the amount of prolactin released. The reason for the decrease in prolactin release is not known. It does not appear to reflect a reduction in the releasable pool of prolactin in the pituitary gland, since the amount of prolactin released in response to thyrotrophin-releasing hormone (TRH) during puer- peral lactation does not alter despite the reduction of release in response to suckling (Tyson et al., 1972).

\section{Control of prolactin secretion in lactation}

Prolactin secretion by the pituitary appears to be controlled predominantly by a prolactin inhibiting factor (PIF) secreted by the hypothalamus (see Meites, 1973). It has been suggested that a prolactinreleasing factor (PRF) may also exist and the release of prolactin as well as TSH in response to TRH had led to the suggestion that TRH may be the physiological PRF (Bowers, Friesen and Folkers, 1973).

The rapid rise in prolactin levels during suckling could represent either cessation of PIF secretion, or release of PRF, both of which would result in an increase in prolactin levels. It appears unlikely that the suckling-induced prolactin release is mediated by release of TRH, since it is not accompanied by release of TSH; injection of TRH induced release of both TSH and prolactin in lactating subjects (Gautvik et al., 1973).

The exact nature of the stimuli associated with suckling which cause prolactin release is not known. It seems probable, however, that the release results from a neural reflex associated with stimulation of the nipple and alveolar area of the breast during suckling. Thus, prolactin release comparable with that seen during suckling may occur after manual breast stimulation in non-pregnant, non-lactating women and even in men (Noel, Suh and Frantz, 1972; Kolodny, Jacobs and Daughaday, 1972). On the other hand, psychological factors associated with breast feeding, in particular anticipation of nursing, do not appear to play an important role in prolactin release since these stimuli do not release prolactin in nursing mothers (Noel et al., 1972).

Although there is no direct quantitative relationship between prolactin release and milk secretion, there is good evidence that prolactin is an essential part of the complex of hormones necessary for milk secretion in the human. Thus, reduction of levels of prolactin by Bromocriptine ( $2 \alpha$-bromergocryptine, CB 154), which affects only prolactin release by the pituitary, is effective in suppression of puerperal lactation (Rolland and Schellekens, 1973; Del Pozo and Flückiger, 1973) and galactorrhoea (Besser et al., 1972; Del Pozo et al., 1972). Prolactin levels are reduced and are maintained within the normal range. On the other hand, growth hormone does not appear to form an essential part of the hormonal complex for lactation, since normal lactation occurs in the complete absence of human growth hormone (Rimoin et al., 1968).

\section{Prolactin and inappropriate lactation}

The well known clinical situation of the galactorrhoea-amenorrhoea syndromes or inappropriate lac- 
tation is normally, but not always, associated with elevated levels of prolactin (Besser et al., 1972; Jacobs and Daughaday, 1973; Frantz, Kleinberg and Noel, 1972; Tolis et al., 1974). Frantz et al. (1972) have reported that patients with galactorrhoea and normal menses have prolactin concentrations within the normal range. It is apparent that milk secretion in these patients is dependent upon enhanced sensitivity of the breast tissue. Secretion is maintained by the elevated levels of prolactin, but lactation will only occur in face of these elevated levels if the mammary tissue has been appropriately primed. Thus, the hormonal control of mammary development on the one hand and milk secretion on the other are not the same, and both require further investigation in man.

\section{Lactational amenorrhoea-prolactin anovulation}

In addition to an essential role in lactation, prolactin in mammals is also concerned with the maintenance of luteal function of the ovary. It has been generally accepted that when prolactin secretion is high, gonadotrophin secretion is reduced and vice versa. Such a relationship between prolactin and the gonadotrophins (LH and FSH) appears to exist in man. It is well known that anovulation often accompanies normal lactation and return to menstruation occurs much more rapidly in women who do not lactate post partum (El Minairi and Foda, 1971). A similar relationship occurs in the well known clinical occurrence of the amenorrhoea-galactorrhoea syndromes. Many cases of galactorrhoea (Thorner et al., 1974a) and normal puerperal lactation (Reyes et al., 1972; Jaffe et al., 1973) are associated with raised circulating prolactin levels and low urinary oestrogen levels in the face of apparently normal LH and FSH levels. Amenorrhoea seems to result from a lack of cyclical release of both FSH and LH, resulting in anovulation. This failure of cyclical discharge of gonadotrophins may result from inadequate release of gonadotrophin-releasing hormone ( $\mathrm{GnRH})$ since, in galactorrhoea, normal or excessive LH and FSH responses to GnRH are seen (Mortimer et al., 1973).

Specific block of prolactin secretion by Bromocriptine in patients with amenorrhoea-galactorrhoea syndromes (Besser et al., 1972; Thorner et al., 1975) and in puerperal lactation (Rolland and Schellekens, 1973) results not only in cessation of milk secretion (see above) but, in the majority of cases of galactorrhoea and in all studied cases of puerperal lactation, a rapid return to gonadal function with cyclical release of $\mathrm{LH}$ and FSH and regular menstruation.

\section{Prolactin and the menstrual cycle}

The relationship between prolactin and gonadotrophin secretion suggests that prolactin may play a role in the control of the menstrual cycle and ovulation. L'Hermite et al. (1972) and Robyn et al. (1973) have reported a peak of prolactin at mid-cycle and higher levels during the luteal than the follicular phases. The peak of prolactin was attributed to the concomitant rise of endogenous oestrogens occurring at this time.

In contrast, several groups of workers have been unable to show consistent changes in prolactin levels during the cycle (Hwang et al., 1971; Tyson and Friesen, 1973; Jaffe et al., 1973; McNeilly, Evans and Chard, 1973; Ehara et al., 1973; McNeilly and Chard, 1974). Although on rare occasions a peak of prolactin occurred coincident with the mid-cycle peak of $\mathbf{L H}$, daily prolactin levels showed wide fluctuations. No relationship appeared to exist between prolactin and the levels of $\mathrm{LH}$ and FSH, oestrogens, progesterone (McNeilly et al., 1973; Ehara et al., 1973; Jaffe et al., 1973), or menstruation (McNeilly and Chard, 1974). Short-term changes of prolactin and gonadotrophins during the day at different stages of the menstrual cycle were also unrelated (Ehara et al., 1973; McNeilly and Chard, 1974), and prolactin secretion appeared to occur in a spike-like manner, similar to that seen in normal male subjects (McNeilly et al., 1974). These results indicate that no specific changes in prolactin levels are associated with events of the menstrual cycle and if there is a relationship between prolactin and gonadotrophins it is not apparent in changing blood levels of these hormones.

The relationship observed during normal or abnormal lactation might operate at the hypothalamic pituitary level. However, injection of TRH, while causing release of prolactin, is not associated with release of either LH or FSH and injection of luteinizing hormone-releasing hormone (LHRH), while releasing $\mathbf{L H}$ and $\mathrm{FSH}$, does not affect prolactin release (Mortimer et al., 1973; McNeilly and Hagen, 1974). In addition, no changes in prolactin levels occur when gonadotrophins are elevated in postmenopausal women (McNeilly, Ormston and Hall, unpublished observations), after clomiphene in normal men (Thorner et al., 1974), or when LH and FSH levels are reduced by long-term treatment with oestrogen (McNeilly, Anderson, Fisher, Mortimer and Thorner, unpublished observations). It appears unlikely, therefore, that any relationship between prolactin and gonadotrophins would reside at the hypothalamic or pituitary level.

\section{Prolactin and the ovary-effects on steroidogenesis}

It has recently become apparent that prolactin may act directly upon the ovary in women, and the relationship between prolactin and the gonadotrophins may be mediated by ovarian steroids (McNatty, Sawers and McNeilly, 1974). Stimulation of ovarian steroidogenesis by gonadotrophin (Pergonal) in the face of high circulating levels of prolactin in either puerperal lactation (Zarate et al., 1972), or galactorrhoea (Thorner et al., 1974) results in a reduced 
steroid response, reflecting apparent ovarian refractoriness. In galactorrhoea, reduction of prolactin levels with Bromocriptine is associated with return of a normal response to Pergonal stimulation (Thorner et al., 1974a), indicating removal of a peripheral block to steroidogenesis. Since Bromocriptine specifically affects only the secretion of prolactin, it would appear that elevated levels of prolactin inhibit steroidogenesis at the site of the ovary. This has been confirmed by McNatty et al. (1974) who have shown that while low levels of prolactin are essential for steroidogenesis, inhibition of progesterone secretion by human granulosa cells in culture occurs when high levels of prolactin are included in the incubation medium.

That a similar situation might occur during the normal menstrual cycle is suggested by changes in prolactin levels within the fluid of the developing ovarian follicle (McNatty et al., 1974). During development, follicular fluid levels of prolactin remain similar to normal circulating blood levels. Just before ovulation, prolactin levels decrease markedly while those of both $\mathrm{LH}$ and progesterone increase. Whether these changes reflect active removal of prolactin from the follicular fluid, or utilization of prolactin for steroidogenesis is unknown, but results indicate that the levels of prolactin within the follicular fluid are not directly related to circulating levels.

Anovulation during lactation and galactorrhoea can thus be explained by the peripheral block of steroidogenesis at the ovary by elevated levels of prolactin resulting in failure of normal steroid feedback to the pituitary and hypothalamus and thus loss of cyclical discharge of LH and FSH (McNeilly, 1974). Reduction of elevated prolactin levels results in removal of this inhibition, return to normal steroidogenesis, cyclical discharge of $\mathbf{L H}$ and FSH, ovulation and normal menstruation. In puerperal lactation, this normally occurs either at weaning or at late stage lactation, when release of prolactin in response to suckling is negligible.

\section{Acknowledgments}

I thank the Wellcome Foundation for support and Dr T. Chard for advice in the preparation of this manuscript.

\section{References}

Besser, G.M., Parke, L., Edwards, C.R.W., Forsyth, I.A. \& MCNeIlly, A.S. (1972) Galactorrhoea: successful treatment with reduction of plasma prolactin levels by brom-ergocryptine. British Medical Journal, iii, 669.

Bowers, C.Y., Friesen, H. \& Folkers, K. (1973) Further evidence that TRH is also a physiological regulator of PRL secretion in man. Biochemical and Biophysical Research Communications, $\mathbf{5 1}, 512$.

Contesso, G.P., Ceriani, B.M. \& Nata, F. (1972) In vitro hormone induced differentiation of human mammary gland. Fourth International Congress of Endocrinology. Abstract No. 265. Excerpta Medica, Amsterdam.
Cowie, A.T. \& Tindal, J.S. (1972) The Physiology of Lactation, Monographs of the Physiological Society No. 22. Edward Arnold Ltd, London.

Del Pozo, E., Brun del Re, R., Varga, L. \& Friesen, H. (1972) The inhibition of prolactin secretion in man by CB-154 (2-Br- $\alpha$-ergocryptine). Journal of Clinical Endocrinology and Metabolism, 35, 768.

Del Pozo, E. \& FlückIger, E. (1973) Prolactin inhibition: experimental and clinical studies. In: Human Prolactin (Ed. by J. L. Pasteels and C. Robyn), p. 291. Excerpta Medica, Amsterdam.

Ehara, Y., Siler, T., VANDenberg, G., Sinha, Y.N. \& Yen, S.S.C. (1973) Circulating prolactin levels during the menstrual cycle: episodic release and diurnal variation. American Journal of Obstetrics and Gynecology, 117, 962.

El MinAIRI, M.F. \& FodA, M.S. (1971) Postpartum lactation amenorrhea. American Journal of Obstetrics and Gyneco$\log y, 111,17$.

Evans, D.G., McNeilly, A.S. \& Chard, T. (1975) Observations on the origin and distribution of prolactin during pregnancy in the human. Journal of Obstetrics and Gynaecology of the British Commonwealth (in press).

FALCONER, F.R. (1972) Uptake and binding of ${ }^{125}$ I-labeled prolactin by mammary tissue. Biochemical Journal, 126, 8p.

FoRsyTH, I.A. \& PARKE, L. (1973) The bioassay of human prolactin. In: Human Prolactin (Ed. by J. L. Pasteels and C. Robyn), p. 71. Excerpta Medica, Amsterdam.

Frantz, A.G. (1972) In: Lactogenic Hormones (Ed. by G. F. W. Wolstenholme and J. Knight), p. 186. Churchill Livingstone, Edinburgh and London.

Franz, A.G., KleinberG, D.L. \& Noel, G.L. (1972) Studies on prolactin in man. Recent Progress in Hormone Research, $28,527$.

GautviK, K.M., Weintraum, B.D., Graeber, C.T., Maloof, F., Zuckerman, J.E. \& TAShian, A.H. (1973) Serum prolactin and TSH: effects of nursing and pyro Glu-HisProNH $\mathrm{N}_{2}$ administration in postpartum women. Journal of Clinical Endocrinology and Metabolism, 37, 135.

Hwang, P., Guyda, H. \& Friesen, H.G. (1971) A radioimmunoassay for human prolactin. Proceedings of National Academy of Sciences of the United States of America, 68, 1902.

JACoBs, L.S. \& Daughaday, W.H. (1973) Pathophysiology and control of prolactin secretion in patients with pituitary and hypothalamic disease. In: Human Prolactin (Ed. by J. L. Pasteels and C. Robyn), p. 189. Excerpta Medica, Amsterdam.

JAFFe, R.B., Yuen, B.H., Keye, W.R. \& Midgley, A.R. (1973) Physiologic and pathologic profiles of circulating human prolactin. American Journal of Obstetrics and Gynecology, 117, 757.

Kolodny, R.C., JacobS, L.S. \& Daughaday, W.H. (1972) Mammary stimulation causes prolactin secretion in nonlactating women. Nature, 238, 284.

L'Hermite, M., Delvoye, P., Nokin, J., Vekemans, M. \& ROBYN, C. (1972) Human prolactin secretion as studied by radioimmunoassay: some aspects of its regulation. In: Prolactin and Carciogenesis (Ed. by A. R. Boyns and K. Griffiths), p. 81. Alpha Omega Alpha, Cardiff.

MCNatTy, K.P., SAWERs, R.S. \& MCNeILly, A.S. (1974) A possible role for prolactin in the control of steroid secretion by the human graafian follicle. Nature, $250,653$.

McNeILly, A.S. (1973) Radioimmunoassay of human prolactin. Proceedings of the Royal Society of Medicine, 66, 863.

McNeilly, A.S. (1974) Prolactin and human reproduction. British Journal of Hospital Medicine, 12, 57.

MCNeilly, A.S. \& ChARD, T. (1974) Circulating levels of prolactin during the menstrual cycle. Clinical Endocrinology, 3. 
McNeilly, A.S., Evans, D.G., \& Chard, T. (1973). Observations on prolactin levels during the menstrual cycle. In: Human Prolactin (Ed. by J. L. Pasteels and C. Robyn), p. 23. Excerpta Medica, Amsterdam.

McNeilly, A.S. \& Hagen, C. (1974) Prolactin, TSH, LH and FSH responses to a combined LHRH/TRH test at different stages of the menstrual cycle. Clinical Endocrinology, 3, 427.

McNeilly, A.S., Sturdy, J., Evans, D.G. \& Chard, T. (1974) Short-term variation in blood levels of prolactin, luteinizing hormone and follicle-stimulating hormone in normal men throughout the day. Journal of Endocrinology, $61,301$.

MeITES, J. (1973) Control of prolactin secretion in animals. In: Human Prolactin (Ed. by J. L. Pasteels and C. Robyn), p. 105. Excerpta Medica, Amsterdam.

Mortimer, C.H., Besser, G.M., MCNeilly, A.S., TunBRIDGE, W.M.G., Gomez-PAN, A. \& Hall, R. (1973) Interaction between secretion of the gonadotrophins, prolactin, growth hormone, thyrotropin and corticosteroids in man: the effects of LH/FSH-RH, TRH and hypoglycaemia alone and in combination. Clinical Endocrinology, 2, 317.

Noel, G.L., SuH, H.K. \& Frantz, A.G. (1972) Induction of prolactin release by breast stimulation in humans. Fourth International Congress of Endocrinology, International Congress Series No. 256. Excerpta Medica, Amsterdam.

Reyes, R.I., Winter, J.S.D. \& Faiman, C. (1972) Pituitaryovarian interrelationships during the puerperium. American Journal of Obstetrics and Gynecology, 114, 589.

Rimoin, D.L., Holzman, B.B., Merimee, T.J., Rabinowitz, D., Barnes, A.C., TySON, J.E.A. \& McKusiK, V.A. (1908) Lactation in the absence of human growth hormone. Journal of Clinical Endocrinology and Metabolism, 28, 1183.

Robyn, C., Delvoye, P., Nokin, J., Vekemans, M., Badawi, M., Perez-Lopez, F.R. \& L'Hermite, M. (1973) Prolactin and human reproduction. In: Human Prolactin (Ed. by J. L. Pasteels and C. Robyn), p. 167. Excerpta Medica, Amsterdam.
Rolland, R. \& Schellekens, L. (1973) A new approach to the inhibition of puerperal lactation. The Journal of Obstetrics and Gynaecology of the British Commonwealth, 80, 945.

ShiU, R.P.C., Kelly, P.A. \& Friesen, H.G. (1973) Receptor assay for prolactin and other lactogenic hormones. Science, 180, 968.

Thorner, M.P., Besser, G.M., Hagen, C. \& MCNeilly, A.S. (1974) The relationship between prolactin and gonadotrophins: effects of clomiphene administration in normal men. Journal of Endocrinology, 63, 43P.

Thorner, M.O., McNeilly, A.S., Hagen, C. \& Besser, G.M. (1975) Long-term treatment of galactorrhoea and hypogonadism with Bromocriptine. British Medical Journal, iv, 419.

Tolis, G., Somma, M., Van Campenhout, J. \& Friesen, H. (1974) Prolactin secretion in sixty-five patients with galactorrhoea. American Journal of Obstetrics and Gynecology, 118, 91.

TuRkington, R.W. (1970) Stimulation of RNA synthesis in isolated mammary cells by insulin and prolactin bound to sepharose. Biochemical and Biophysical Research Communications, 41, 1362.

Turkington, R.W., Frantz, W.I. \& Majumder, G.C. (1973) Effector-receptor relations in the action of prolactin. In: Human Prolactin (Ed. by J. L. Pasteels and C. Robyn), p. 24. Excerpta Medica, Amsterdam.

Tyson, J.E., HWANG, P., GuYda, H. \& Friesen, H.G. (1972) Studies of prolactin secretion in human pregnancy. American Journal of Obstetrics and Gynecology, 113, 14.

Tyson, J.E. \& FrIEsEN, H.G. (1973) Factors influencing the secretion of human prolactin and growth hormone in menstrual and gestational women. American Journal of Obstetrics and Gynecology, 116, 377.

Zarate, A., Canales, E.S., Soria, J., Ruiz, F. \& McGregor, C. (1972) Ovarian refractoriness during lactation in women: effect of gonadotropin stimulation. American Journal of Obstetrics and Gynecology, 112, 1130. 